\title{
ISLAMPHOBIA DAN ANTISEMITISME MODERN PADA MEDIA ONLINE JERMAN
}

\author{
Ajeng Dianing Kartika \\ Universitas Negeri Surabaya, ajengkartika@unesa.ac.id
}

\begin{abstract}
Islamophobic and Antisemitism have nowadays become trending topics in Germany. The rise of muslims population in Germany during migration crisis that cause pro and contra in the society can be the main cause of the Islamophobic in the country lead by Angela Merkel. In the other side there is another phenomenon called antisemtism that historically has occurred since the Nazi's era. Currently this phenomenon suddenly rise up during migration crisis and it has been strongly discussed after the controversy created by duo rappers Kollegah (Felix Blume) and Farid Bang (Farid El Abdellaoui) who took home the prize for their anti-semitism songs in album Jung, Brutal, Gutaussehend 3. Pro and contra appears and it becomes trending topic in German online newspaper beside the islamophobia that's still debatable. Even though these two phenomenon has a similiarity, namely 'anxiety feeling or extreme fear of something', there is different strategies used by the Press in Germany. Crictical analysis is needed to reveal specific strategies applied and the impact of the kind of strategies on the representation of Muslims and Jews in Germany. Based on critical discourse studies, it can be concluded that the German online newspaper define Islam as out group who create islamophobic. But, Jews are represented differently as a victim of anti-Semitism.
\end{abstract}

Keywords: critical discourse analysis, islamophobia, new antisemitism

\section{PENDAHULUAN}

Islamophobia dan Antisemitisme kini menjadi topik yang sedang tren di Jerman. Munculnya populasi muslim di Jerman selama krisis migrasi yang menyebabkan pro dan kontra di masyarakat dapat menjadi penyebab utama dari Islamofobia di negara yang dipimpin oleh Angela Merkel. Di sisi lain ada fenomena lain yang disebut antisemtisme yang secara historis telah terjadi sejak era Nazi. Saat ini fenomena ini tiba-tiba muncul selama krisis migrasi dan telah sangat dibahas setelah kontroversi yang diciptakan oleh duo rappers Kollegah (Felix Blume) dan Farid Bang (Farid El Abdellaoui) yang membawa pulang hadiah untuk lagu anti-semitisme mereka di album Jung, Brutal, Gutaussehend 3. Pro dan kontra muncul dan itu menjadi trending topic di surat 
kabar online Jerman di samping islamophobia yang masih bisa diperdebatkan. Meskipun kedua fenomena ini memiliki kesamaan, yaitu 'perasaan cemas atau ketakutan yang ekstrim terhadap sesuatu', ada berbagai strategi yang digunakan oleh Pers di Jerman. Analisis ketat diperlukan untuk mengungkapkan strategi spesifik yang diterapkan dan dampak dari jenis strategi pada representasi Muslim dan Yahudi di Jerman. Berdasarkan studi wacana kritis, dapat disimpulkan bahwa surat kabar online Jerman mendefinisikan Islam sebagai kelompok luar yang menciptakan islamophobic. Tapi, orang Yahudi diwakili berbeda sebagai korban anti-Semitisme.

Antisemitisme modern, yang terbentuk di Jerman pada abad ke-19, muncul paling tidak sebagai reaksi permusuhan terhadap emansipasi, lefal enfranchisement dan peningkatan mobilitas sosial yang dinikmati oleh anggota minoritas Yahudi. Perdebatan seputar lslam di Eropa todaV mungkin juga dijelaskan sebagian oleh peningkatan partisipasi umat Islam dalam masyarakat yang lebih luas. Secara umum bukan masjid halaman belakang yang menimbulkan respons yang tidak bersahabat, itu adalah rumah ibadah yang lebih menonjol dan beragama yang terlihat dalam lanskap perkotaan dan yang menunjukkan Muslim sebagai anggota masyarakat Eropa. Satu paralel lebih lanjut ke perdebatan abad ke-19 adalah bahwa orang-orang Yahudi dituduh memisahkan diri dari budaya arus utama karena agama mereka. Mereka bahkan diyakini memendam perasaan bermusuhan terhadap mayoritas, menolak untuk mengintegrasikan dan menahan tidak ada kesetiaan kepada Negara

Prasangka seperti itu juga terbukti dalam perdebatan tentang lslam hari ini. Di kalangan akademis, telah dikemukakan bahwa rasisme budaya terhadap umat Islam berfungsi serupa dalam proses integrasi Eropa seperti yang dilayani oleh antisemitisme di negara-negara Eropa pada abad ke-19. 
Dalam kedua kasus itu, dimulai dengan fase percepatan perubahan sosial yang tampaknya mengancam tatanan sosial yang mapan dan mengarah pada perpecahan yang lebih jelas antara "kita" dan orang asing yang dicurigai. Karenanya, pemanggilan identitas "barat" berfungsi untuk menstabilkan konstruk identitas nasional, sebagaimana perdebatan tentang "budaya terkemuka" (Leitkultur), yang berulang kali digelar di Jerman, menunjukkan. Perdebatan semacam itu sering dilontarkan dengan pernyataan bahwa lslam pada dasarnya tidak sesuai dengan "budaya Barat". Klaim ini memiliki resonansi yang signifikan di dalam pandangan dunia dari populasi mayoritas: menurut survei yang representatif, sekitar 39olo dari semua orang Jerman akan setuju dengan pernyataan "dengan begitu banyak Muslim di sekitar, saya dari sepuluh merasa seperti orang asing di negara saya sendiri." Ketakutan dikuasai oleh orang asing dan terasing di tanahnya sendiri menyiratkan bahwa menjadi Muslim dan menjadi orang Eropa atau Jerman adalah identitas yang bertentangan dan tidak kompatibel - yaitu, bahwa seorang Musllm tidak dapat menjadi orang Jerman "Eropa" yang tepat. Pertanyaan tentang kepemilikan nasional ini - yang sama dengan retoreralisasi retoris - adalah tema yang akrab bagi sejarah antisemitisme Jerman pada abad ke-19, yang masih banyak dihadapi oleh kaum Yahudi Jerman hari ini. mantan Ketua Dewan Pusat Yahudi di Jerman, lgnatz Bubis, misalnya, pernah diberi selamat selama kunjungan kenegaraan oleh Presiden Weizman lsira atas pidato sukses presiden "nya". Rasisme anti-Muslim dengan demikian berbagi dengan antisemitisme suatu pengelompokan objek-objeknya menggunakan kriteria agama dan etnis, dan mengidentifikasi mereka dengan kolektif transnasional. Analogi struktural antara wacana anti-lslam dan antisemitic juga muncul dalam penggunaan retorik teks-teks keagamaan. Sama seperti para pakar anti-Muslim saat ini yang ingin mendukung allegatlons mereka dengan referensi ke Alquran, pamflet antisemit dari abad ke-19 menggunakan argumen yang sama ketika mengacu 
pada Talmud. Sering juga ada kesejajaran dalam kesimpulan bahwa para pembaca yang bermusuhan menarik dari Talmud dan Alquran.

Saat ini tren anti-Semitisme dan islamophobia Jerman berkembang dengan cara yang berbeda. Statistik yang diambil dari surat kabar Suddeutsche Zeitung menyatakan bahwa islamophobia telah meningkat di negara ini, yaitu sejak masuknya banyak migran dari negara-negara muslim. Krisis migrasi yang telah terjadi sejak 2013 telah menyebabkan perselisihan. Pro dan kontra di Jerman tentang keberadaan migran muslim telah menjadi tema penting di media massa. Beberapa orang menyebut para migran sebagai 'ancaman' bagi Jerman tetapi tidak sedikit dari orang-orang Jerman yang merasa kasihan kepada mereka karena mereka harus pindah dari negara mereka, yang masih dalam keadaan perang. Di sisi lain Antisemitisme yang sudah terlupakan tibatiba muncul sebagai berita panas di Jerman selama krisis migrasi. Setelah masuknya pengungsi, dilaporkan oleh The Washington Post bahwa ada 947 insiden serangan anti-Semit, ancaman dan vandalisme di kota itu pada tahun 2017 - hampir dua kali lipat dari tahun sebelumnya.

Berfokus pada keberadaan anitisemitisme dalam munculnya islamophobia selama krisis migrasi sebagai studi kasus dan dengan menerapkan alat-alat metodologis seperti analisis wacana kritis, konstruksi, representasi, dan penolakan gagasan ini di media akan diperiksa. Media selalu menjadi alat yang kuat dan berpengaruh untuk menyebarluaskan pengetahuan di masyarakat. Salah satu pengaruhnya ada hubungannya dengan bagaimana masyarakat menciptakan pengetahuan tentang situasi melalui presentasi. Media adalah alat yang memiliki kekuatan untuk memengaruhi pendapat dan keyakinan orang; mereka memiliki kekuatan untuk menghasilkan 'pengetahuan' melalui fakta dan fiksi dengan memutuskan apa yang orang harus fokuskan perhatian mereka. Oleh karenanya penelitian ini memfokuskan pada strategi 
media Jerman dalam menuliskan pemberitaan tentang Islamphobia dan antisemitisme.

\section{Teori}

Strategi media massa dalam menuliskan pemberitaan dapat dianalisis secara terperinci menggunakan kajian wacana kritis. Tugas utama kajian wacana kritis adalah menguraikan relasi kuasa, dominasi dan ketimpangan yang diproduksi dalam wacana (Van Dijk, dalam Tannen dkk, 2001). Kata kritis menyiratkan pengkajian yang lebih mendalam terhadap gagasan yang secara implisit dikandung suatu wacana. Melakukan pengkajian wacana secara kritis mengharuskan kita untuk menemukan gagasan yang mendasari produksi wacana. Sependapat dengan Van Dijk, Renkema (2004:282) dalam bukunya yang berjudul relasi kuasa yang terdapat dalam masyarakat. Menurutnya kajian wacana kritis dilakukan dengan tujuan untuk mendeteksi masalah-masalah sosial dan politik yang terjadi di masyarakat, terutama masalah diskriminasi. Kajian wacana kritis menempatkan bahasa sebagai sarana perwujudan kuasa pihak tertentu. Selain itu bahasa juga menjadi sarana pertarungan ideologi bagi pelibat wacana untuk mengabsahkan kuasanya.

Dalam kajian wacana kritis ideologi berkaitan dengan fondasi yang digunakan dalam proses produksi wacana. Hodge dan Kress (1979:6) mengungkapkan bahwa ideologi adalah bentuk ide sistematis yang diproduksi melalui pandangan tertentu yang mempengaruhi proses produksi wacana. Lebih terperinci, van Dijk (2006:279) menjelaskan bahwa ideologi dihasilkan melalui proses kognitif dan sosial. Melalui sudut pandang kognitif, ideologi adalah sistem keyakinan yang tersimpan dalam memori jangka panjang. Ideologi tidak bersifat individual melainkan sosial. Sistem keyakinan yang dimiliki oleh seorang individu dipengaruhi oleh lingkungan sosialnya. Ideologi menjadi keyakinan dasar yang dimiliki oleh sebuah kelompok dan dihayati bersama oleh seluruh 
Ajeng Dianing Kartika, Islamphobia dan Antisemitisme... (hlm.142-154 )

anggota kelompok. Ideologi menjadi fondasi suatu kelompok dalam merepresentasikan fenomena sosial yang ada. Wacana menjadi sarana untuk menyampaikan fenomena sosial yang tengah terjadi pada msyarakat. Ideologi yang dimiliki pihak yang memproduksi wacana akan mempengaruhi bagaimana fenomena sosial itu direalisasikan pada wacana melalui media bahasa.

Van Dijk mengklasifikasikan dimensi wacana menjadi 3 elemen, yakni :

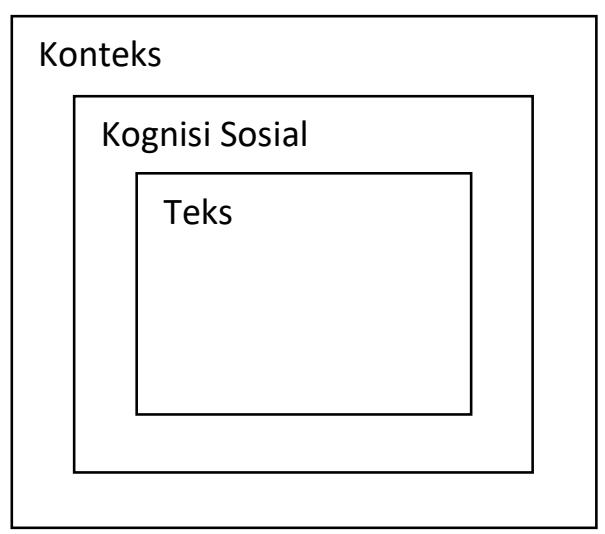

Bagan 1. Dimensi Penyusun Wacana (van Dijk, 2008)

Dimensi tekstual yang diklasifikasikan Van Dijk menjadi dua struktur, yakni makro dan mikro yang memiliki fungsi deskriptif, yakni mendeskripsikan struktur wacana. Dimensi kontekstual memiliki fungsi interpretasi. Interpretasi dilakukan dengan cara menghubungkan antara dimensi tekstual dengan properti kontekstual yang meliputi proses kognitif dan faktor sosiokultural. Keterlibatan proses kognitif inilah yang menghadirkan dimensi baru yang disebut kognisi sosial dalam wacana sebagai jembatan yang menghubungkan antara dimensi tekstual dan kontekstual (Van Dijk, 1988:24-25). Kognisi sosial yang dimaksudkan adalah proses mental dan kognisi penulis, dalam penelitian ini wartawan, dalam proses produksi wacana. 
Dimensi tekstual terdiri atas struktur makro dan mikro teks yang saling berkaitan. Pada level makro yang menjadi focus adalah topic global wacana yang diperoleh melalui proposisi makro dan skematik teks. Skematik teks juga memegang peranan yang signifikan dalam proses pengkajian wacana kritis. Skematik teks yang kemudian oleh van Dijk (1988:26) dikategorikan tersendiri sebagai superstruktur teks mengacu pada bentuk umum teks, mana yang ditampilkan di awal dan yang dipilih untuk ditampilkan di bagian akhir, focus yang dipilih untuk headline dan lead, komentar siapa yang dipilih untuk disertakan sebagai pendukung isi berita. Skematik wacana di susun van Dijk (1988: 55) secara terperinci pada bagan berikut :

News

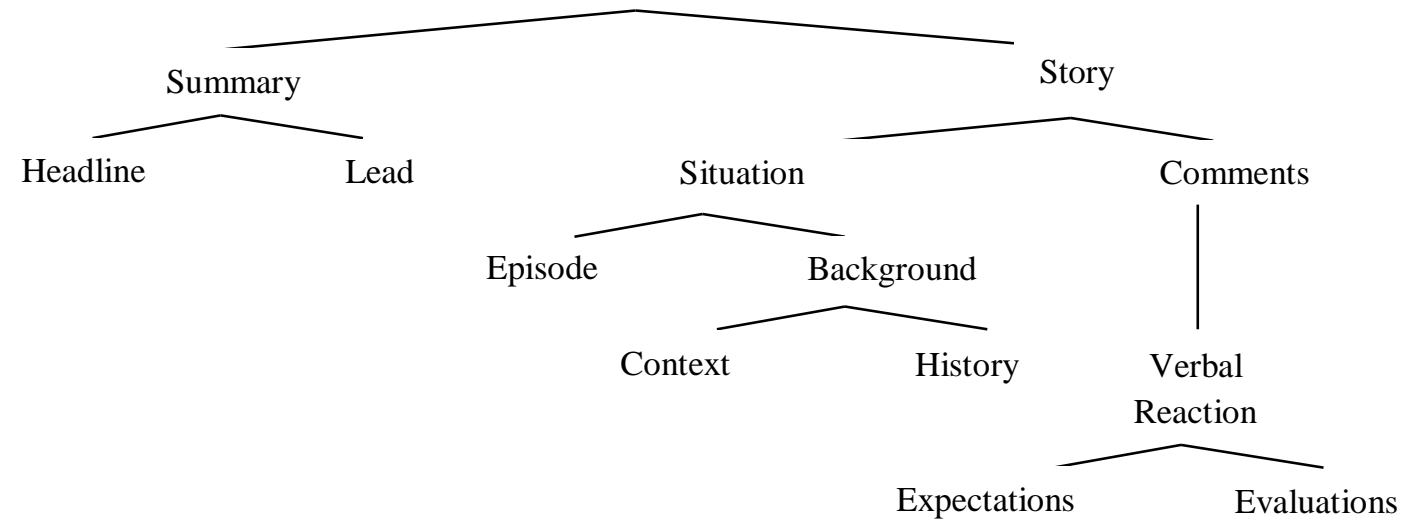

Bagan 2. Skematik Teks Berita

Dimensi teks pada level makro dan mikro memiliki keterkaitan satu sama lain. Setelah melakukan analisis pada level makro wacana. Struktur mikro membedakan antara makna dan bentuk realisasinya pada struktur permukaan wacana seperti kata, frasa, klausa, dan bentuk kalimat. Makna lokal wacana dapat dilihat melalui proposisi mikro sebagai satuan makna terkecil dari suatu kalimat. Sesuai dengan pendapat van Dijk (2006:125) hal yang mempengaruhi makna lokal wacana yang berkaitan antara lain 1) Koherensi lokal, 2) Manifestasi makna wacana (implisit vs eksplisit), 3) Granularitas (tingkat detail kalimat), 4) http://journal.unesa.ac.id/index.php/paramasastra |148 
Ajeng Dianing Kartika, Islamphobia dan Antisemitisme... (hlm.142-154 )

Modalitas, 5) Pembuktian, 6) Penyangkalan, 7) Pilihan leksikal, 8)Keragaman sintaksis, dan 9) Retorika.

\section{HASIL DAN PEMBAHASAN}

Istilah "Islamophobia" awalnya dianggap sebagai gagasan oleh politisi di akhir 1990-an untuk fokus pada fungsi retoris, tindakan, dan perilaku terhadap Islam dan komunitas Muslim di Barat. Kata ini terdiri dari dua bagian, yaitu "Islam" (agama Muslim) dan "fobia" yang didefinisikan oleh Oxford Dictionary (2005) sebagai "rasa takut atau kebencian yang tidak masuk akal yang kuat dari hal tertentu". Gagasan ini telah didefinisikan oleh beberapa peneliti berbeda: Lee dkk. (2009: 93) mendefinisikan Islamophobia sebagai "ketakutan terhadap Muslim dan agama Islam". Dalam salah satu definisi yang lebih terperinci disebutkan bahwa "Islamophobia adalah penolakan terhadap Islam, Muslim kelompok dan individu Muslim berdasarkan prasangka dan stereotip uang berkembang di kalangan masyarakat". Definisi ini mungkin memiliki elemen emosional, kognitif, evaluatif, serta berorientasi pada tindakan (misalnya diskriminasi, kekerasan). Di sisi lain ada fobia yang melibatkan subjek berbeda yang disebut anti-Semitisme, yakni penolakan terhadap segala sesuatu yang berkaitan dengan Yahudi.

Pada penelitian ini terdapat 4 berita tentang Islamophobia dan anti-Semitisme dari surat kabar online konservatif kanan Die Welt yang dipilih objek kajian, sebagai berikut :

a. https://www.welt.de/politik/deutschland/article178494258/RadikalisierungStudie-entdeckt-Gemeinsamkeiten-zwischen-Islamisten-undNeonazis.html?wtrid=onsite.onsitesearch

b. https://www.welt.de/politik/deutschland/article174861632/Kretschmerueber-radikale-Muslime-Wir-erleben-ein-neuesKriminalitaetsphaenomen.html?wtrid=onsite.onsitesearch 
c. https://www.welt.de/regionales/sachsen-anhalt/article176891925/Haseloffwarnt-vor-neuem-Antisemitismus.html?wtrid=onsite.onsitesearch

d. https://www.welt.de/debatte/kommentare/article176940885/Antisemitismu s-Fluechtlinge-und-Israel.html?wtrid=onsite.onsitesearch

\section{$\underline{\text { Analisis makro }}$}

Pada level makro teks yang dianalisis adalah tema global wacana. Sesuai dengan pendapat van Dijk (2008) tema global diperoleh melalui proposisi makro yang menyusun wacana. Proposisi makro dihasilkan melaui penerapan kaidah makro, yakni 1)penghapusan, 2)generalisasi, dan 3)rekonstruksi, pada rangkaian proposisi setiap paragraph teks berita. Berdasarkan penerapan kaidah makro diperoleh proposisi makro sebagai berikut :

Tabel 1

Proposisi Makro

\begin{tabular}{|c|c|}
\hline \multirow{6}{*}{ 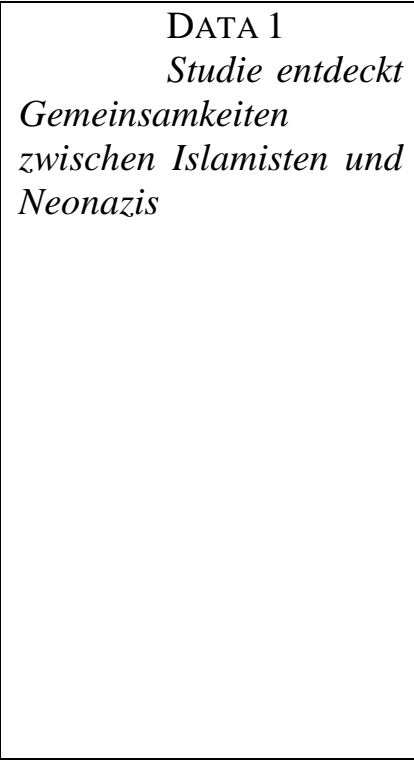 } & $\begin{array}{l}\text { Eine Studie zeigt, dass Islamisten und Neonazis } \\
\text { haben viel gemein }\end{array}$ \\
\hline & $\begin{array}{l}\text { Feindlichkeit gegen Muslime und Islamismus ist } \\
\text { radikaler und verbreiteter als Neonazis }\end{array}$ \\
\hline & $\begin{array}{l}\text { Institut für Demokratie und Zivilgesellschaft hat von } \\
\text { 2013-2017 eine Studie mit dem Thema „,Hassliebe: } \\
\text { Islamfeindlichkeit, Islamismus und die Spirale } \\
\text { gesellschaftlicher Polarisierung “ gemacht }\end{array}$ \\
\hline & $\begin{array}{l}\text { Islamismus und Rechtsextremismus treffen sich den } \\
\text { Wissenschaftlern zufolge ideologisch im Antisemitismus, in } \\
\text { Verschwörungsmythen und im Ziel homogener Gesellschaften }\end{array}$ \\
\hline & $\begin{array}{l}\text { islamistische Kommunikation in den sozialen } \\
\text { Netzwerken stark eingeschränkt und ihre Rhetorik ,, deutlich } \\
\text { gemäßigter“ als noch Anfang } 2017 \mathrm{sei}\end{array}$ \\
\hline & $\begin{array}{l}\text { Islamistische Radikalisierung, antimuslimischer } \\
\text { Rassismus und Antisemitismus müssen zusammen gedacht } \\
\text { werden }\end{array}$ \\
\hline \multirow{3}{*}{$\begin{array}{l}\text { „Wir erleben } \\
\text { neues } \\
\text { Kriminalitätsphänomen“ }\end{array}$} & $\begin{array}{c}\text { Für Sachsens Ministerpräsident Kretschmer } \\
\text { gehörten bestimmte Muslime nicht zu Deutschland }\end{array}$ \\
\hline & $\begin{array}{l}\text { Der Regierungschef zeigte Verständnis für } \\
\text { Kommunen, die so wie das sächsische Freiberg oder Cottbus } \\
\text { in Brandenburg keine Flüchtlinge mehr aufnehmen wollen }\end{array}$ \\
\hline & $\begin{array}{l}\text { Es gibt objektiv ein Problem, was die Integration } \\
\text { angeht. Es fehlen beispielsweise Plätze in Kindergärten und }\end{array}$ \\
\hline
\end{tabular}

http://journal.unesa.ac.id/index.php/paramasastra |150 


\begin{tabular}{|c|c|}
\hline & $\begin{array}{l}\text { Schulen. Und es gibt Probleme mit Menschen, die sich nicht } \\
\text { an unsere Werte und Gesetze halten wollen }\end{array}$ \\
\hline & $\begin{array}{l}\text { jugendliche Migranten in größeren Gruppen } \\
\text { auftreten und sich von normaler Ansprache nicht } \\
\text { beeindrucken lassen }\end{array}$ \\
\hline & $\begin{array}{l}\text { Wir erleben ein neues Kriminalitätsphänomen. Und } \\
\text { Abschiebungen funktionieren nicht, weil Flüchtlinge ihre } \\
\text { Identität verschleiern }\end{array}$ \\
\hline & $\begin{array}{l}\text { Horst Seehofer will das Land nicht spalten, sondern } \\
\text { wieder zusammenführen }\end{array}$ \\
\hline & $\begin{array}{l}\text { das Integrations-Leitbild, das wir haben müssen, das } \\
\text { muss basieren auf den republikanischen Werten des } \\
\text { Grundgesetzes, auf unserer Rechtsordnung, und für die kann } \\
\text { es keinen Rabatt geben für niemanden }\end{array}$ \\
\hline & $\begin{array}{l}\text { Generalsekretär des Zentralrats der Muslime findet, } \\
\text { dass Die erneute Debatte der Islamfeindlichkeit wollen die } \\
\text { Gesellschaft spalten }\end{array}$ \\
\hline \multirow{3}{*}{$\begin{array}{l}\text { DATA 3 } \\
\text { Haseloff warnt } \\
\text { vor } \begin{array}{l}\text { neuem } \\
\text { Antisemitismus }\end{array}\end{array}$} & $\begin{array}{l}\text { Jegliche Form von Antisemitismus - von rechts wie } \\
\text { von links - wird in unserer Gesellschaft nicht geduldet }\end{array}$ \\
\hline & $\begin{array}{l}\text { Haseloff hatte betont, dass es wichtig ist, der Ausbau } \\
\text { der Kontakte mit Israel in Wirtschaft, Wissenschaft, Sport und } \\
\text { Kultur sei }\end{array}$ \\
\hline & $\begin{array}{l}\text { Laut dem Bundesinnenministerium sind im } \\
\text { vergangenen Jahr bundesweit rund } 1500 \text { antisemitische } \\
\text { Delikte erfasst worden }\end{array}$ \\
\hline \multirow{8}{*}{\begin{tabular}{l}
\multicolumn{2}{|c|}{ DATA 4 } \\
Jeder \\
Flüchtling sollte ein \\
Bekenntnis $\quad z u \quad$ Israel \\
unterschreiben
\end{tabular}} & Importierte Antisemitismus passiert in Deutschland \\
\hline & $\begin{array}{l}\text { Zuwanderung ist eine Ursache importierte } \\
\text { Antisemitismus }\end{array}$ \\
\hline & $\begin{array}{l}\text { Mehr Muslime bedeuten nicht automatisch mehr } \\
\text { Antisemitismus. }\end{array}$ \\
\hline & $\begin{array}{l}\text { Die Juden verwirrt sich, wie Deutschland angesichts } \\
\text { seiner Vergangenheit Millionen Menschen ins Land lassen } \\
\text { könne, ohne sie im Hinblick auf Judenhass zu,, überprüfen“. }\end{array}$ \\
\hline & $\begin{array}{c}\text { Ein effektives Screening-Verfahren für die } \\
\text { Flüchtlinge in Deutschland ist wichtig zu entwickeln }\end{array}$ \\
\hline & $\begin{array}{l}\text { Die deutsche Regierung muss Jede Flüchtlinge } \\
\text { informieren, dass die Sicherheit Israels zur deutschen } \\
\text { Staatsräson gehört, dass jüdisches Leben hier gefördert und } \\
\text { der Antisemitismus nicht geduldet wird. }\end{array}$ \\
\hline & $\begin{array}{l}\text { Es wäre besser, wenn Die Flüchtlinge muss die } \\
\text { Zustimmung über Israels Sicherheit und Antisemtismus } \\
\text { unterschreiben }\end{array}$ \\
\hline & Die solche Unterschrift gilt als Zeichen für die \\
\hline
\end{tabular}

151 | http://journal.unesa.ac.id/index.php/paramasastra 
Flüchtlinge, die vielleicht Judenhass haben

Proposisi-proposisi makro di atas secara skematik disusun dengan tujuan atau pesan tertentu yang ingin disampaikan kepada pembaca.

$\underline{\text { Analisis mikro }}$

Struktur makro dalam berita diperkuat oleh struktut mikro. Hal ini dapat dicermati pada beberapa pilihan leksikal yang digunakan untuk menggambarkan aktor dalam berita, yaitu Islam, Muslim, Yahudi, dan Israel. Islam dan Muslim digambarkan sebagai kelompok yang terkait dengan radikalisme (Radikal), anti liberal (anti Liberal), rasisme (Rasismus), dan antisemitisme (Antisemitismus).

(a) Muslimische Migrantengruppen haben das Potenzial, Radikalismus in der Gesellschaft zu verbreiten, insbesondere für diejenigen, die jemals Opfer eines Krieges geworden sind

(b) Für die antiliberale Gruppe muss es schwierig sein, die neue liberale Gesellschaft in ihnen zu akzeptieren

Pada kalimat (a) dan (b) secara eksplisit wartawan Die Zeit mendeskripsikan kelompok muslim sebagai kelompok yang berpotensi untuk menyebarkan radikalisme dan anti liberal. Selain secara eksplisit, mengutip kalimat implisit, wartawan berikut dapat dicermati bahwa mereka mencoba untuk menunjukkan bahwa kelompok muslim masih belum mematuhi aturan-aturan yang ada di Jerman.

(c) „Aber das Integrations-Leitbild, das wir haben müssen, das muss basieren auf den republikanischen Werten des Grundgesetzes, auf unserer Rechtsordnung, und für die kann es keinen Rabatt geben für niemanden." $\rightarrow$ menyiratkan bahwa kelompok muslim juga harus mematuhi peraturan perundang-undangan di Jerman tanpa pengecualian.

(d) "Alle in Deutschland lebenden Menschen müssen wissen: Jegliche Form von Antisemitismus - von rechts wie von links - wird in unserer Gesellschaft nicht geduldet" 
Penggunaan modal muss dalam kalimat (c) dan (d) menyiratkan bahwa ada ketimpangan kekuasaan antara Jerman dan Muslim, sehingga mereka memiliki hak untuk mewajibkan umat Islam untuk mengikuti kehendak mereka, yaitu mematuhi konstitusi dan aturan Jerman. Dari (c) kita juga dapat mengamati bahwa Jerman menyatakan secara implisit bagaimana orang Yahudi memiliki posisi yang penting di negara ini. Orang Yahudi dan Israel diposisikan sebagai korban antisemitisme yang disebabkan oleh migran. Strategi mikro lain yang berlaku adalah granularity atau tingkat deskripsi yang ditulis oleh jurnalis. Mereka lebih suka menggunakan informasi detail untuk menekankan sisi buruk kaum muslimin. Muslim dikategorikan sebagai kelompok luar yang bukan merupakan bagian dari kelompok bersama dengan Jerman dan Israel.

\section{SIMPULAN}

Berdasarkan hasil analisis yang diterapkan pada 4 teks berita majalah online Die Zeit ditemukan bahwa wartawan cenderung menonjolkan sisi negatif Islam dan Muslim. Di sisi lain kelompok Yahudi ditempatkan sebagai korban yang harus dilindungi dengan adanya antisemtisme modern yang kembali muncul di Jerman pasca ledakan pengungsi yang berasal dari negara muslim.Secara linguistik hal ini dapat dibuktikan melalui pilihan leksikal yang digunakan dan penerapan manifestasi makna implisit dan eksplisit untuk menekankan sisi negative kelompok muslim.Perspektif wartawan dalam mendeskripsikan kelompok muslim dan Yahudi dipengaruhi oleh kognisi sosial mereka sebagai masyarakat Jerman dan wartawan Die Zeit.

153 | http://journal.unesa.ac.id/index.php/paramasastra 


\section{DAFTAR PUSTAKA}

Kress, Gunther dan Robert Hodge. (1979). Language as Ideology. London: Routledge and Kegan Paul.

Van Dijk, Teun A. (1988). News as Discourse. New Jersey: Lawrence Erlbaum Associates Publisher.

Van Dijk, Teun A. (1993). Principles of Critical Discourse Analysis. Dalam Teun A. Van Dijk (Ed.), Studies in Critical Discourse Analysis (hlm. 249-283). Special issue of Discourse \& Society.

Van Dijk, Teun A. (2001). 'Critical Discourse Analysis' dalam D. Tannen, D. Schiffrin \& H. Hamilton. (2001) .Handbook of Discourse Analysis (hlm.352-371). Oxford: Blackwell.

Van Dijk, Teun A. (2006). Ideology and Discourse. Barcelona : Pompeu Fabra University.

Van Dijk, Teun A. (2006). Politics, Ideology, and Discourse. Elsevier

Van Dijk, Teun A. (2008). Discourse and Context, A Sociocognitive Approach. New York : Cambridge University Press 